International Journal of Child, Youth and Family Studies (2014) 5(1): 158-179

\title{
ABORIGINAL YOUTH SUICIDE PREVENTION: A POST-COLONIAL COMMUNITY-BASED APPROACH
}

\section{Darien Thira}

\begin{abstract}
Aboriginal youth suicide is often understood as a (mental) health crisis, so that prevention efforts are designed to promote the early recognition and intervention that is appropriate for any biological disease. This article redefines Aboriginal youth suicide as a community crisis with a social cause (i.e., the impacts of colonization) and cultural "cure" rooted in the reclaiming of wellness through the contemporary expression of traditional values. Using the "Through the Pain to Wellness: Community-Based Suicide Prevention Program” (which has served Aboriginal communities across Canada for the last 20 years) as an example, an introduction to suicide pre-/inter-/post-vention using a post-colonial community resource model in offered. The program provides a blend of post-colonial consciousness raising (to enhance empowerment), mental health promotion (to enhance awareness), intervention skills training (to enhance capacity), and community development (to enhance wellness) in order to mobilize communities as they develop and implement a strengths-based suicide prevention strategy to promote individual, family, and community resilience in the face of suicide.
\end{abstract}

Keywords: Aboriginal, Native, First Nations, Indian, youth, suicide, prevention, intervention, postvention, post-colonial, community development, resilience, mental health promotion, wellness program

Darien Thira, Ph.D., is a Registered Psychologist who serves as a community development and wellness consultant for many Aboriginal communities across Canada. He offers training workshops and clinical consultation related to post-colonial community mobilization and development, trauma healing, addiction, and suicide; he is also a Graduate School instructor and mental health clinician/assessor at an Aboriginal drug/alcohol treatment centre. In relation to suicide, the culturally driven community-based prevention program described in this paper "Through the Pain to Wellness" - has been used in over 50 Aboriginal communities across Canada and Australia. E-mail: darien@thira.ca 
International Journal of Child, Youth and Family Studies (2014) 5(1): 158-179

Aboriginal youth suicide is often understood as a mental health crisis with medical (i.e., psychiatric) solutions. While this is true in some cases, a post-colonial approach redefines youth suicide as a community crisis, resulting from the ongoing insults of colonization, with social and cultural solutions. Based upon the academic/research literature, 20 years of Aboriginal community development work, and the findings of a qualitative study with members of the Coast Salish and Kwakwaka'wakw Nations who transitioned from their own suicidal crisis to become contributors to the wellness of their communities, this paper offers:

1. A brief discussion of post-colonial theory, its application to Canadian Aboriginal social history, and the notion of suicide "prevention"; and follows with

2. A review of the key ideas that guide a culturally-driven, community-based youth suicide prevention program that has been utilized by Aboriginal communities in Canada for over 20 years.

\section{Post-colonial Approach}

According to the post-colonial perspective, the role and status of mainstream psychology is maintained by its "individualistic position," which suggests that the self can be understood as an independent cognitive agent, that experience is a subjective mental state that is universal to humanity. In this universalist position, meaningful generalizations are made from the study of individuals; society and culture are considered to be the aggregate product of individuals (e.g., Bhargava, 1992; Schwartz , 1992; Youngblood Henderson, 2000). The individualist/universalist stance offers the appearance of a value-neutral approach to psychology, since socio-cultural and historical differences between cultural groups are rendered invisible. The risk is the depreciation and pathologizing of individuals and cultures that lie outside of the "norm" (i.e., those experiencing oppression) and that socio-cultural problems are "individualized” (Kleinman, 1988; Lykes, 1996; Satzewich, 1998). As a result, mainstream psychological treatment and research with oppressed peoples may promote the subjugation of oppressed groups by the dominant culture, by reducing the distress associated with oppression to a psychological or medical concern, rather than a natural (i.e., normal) response to the oppression itself. Further, the focus on individuals alone denies the strengths of the social context, particularly within cultures that emphasize the collective (e.g., Dana, 1996; Prilleltensky, 1994; Smith, 1998). Mental health is isolated from its socio-historical context through the medicalization of psychopathology, healing, and resilience. The post-colonial critique argues that mental illness/health is a psychological social judgment - one in which a normal (i.e., natural) behavioural response to a difficult sociocultural situation is individualised (i.e., understood to be located within the person, to be "personal”) and pathologised for human (i.e., psycho-socio-cultural-historical) phenomena to be reduced by the "medical gaze" to a "symptom" of a mental or physical disorder (Foucault, 1973). Empowerment is thus conceived as psychic (rather than social or political) liberation and the pursuit of personal "adjustment” (i.e., learning to "cope”) is exchanged for social change. Issues of history, privilege, and marginalization are avoided as knowledge is understood to be personally derived rather than socially constituted (Atleo, 1997; Gutierrez \& Lewis, 1999; Heenan, 1996; Ingleby, 1980). As a result, dominant psychological methodologies are used to 
International Journal of Child, Youth and Family Studies (2014) 5(1): 158-179

colonize political terrain and uphold the position of the dominant power structure (Burman, 1996; Billington, 1996; Wade, 2000). The following section offers a socio-historical foundation for the prevention of Aboriginal youth suicide.

\section{The Four Waves of Aboriginal Colonization in Canada}

Aboriginal people in Canada have been profoundly impacted by a history of colonization (e.g., Kirmayer, Tate, \& Simpson, 2009). For clarity, colonial interventions in Canada can be broken down into four waves: The first, legal wave declared Aboriginal people to be "wards of the state" and the Department of Indian Affairs was created to manage the lives of Aboriginal people, enforce legislation, and exert political control over the communities (Harris, 2002). Traditional practices, which served spiritual, social, personal, and economic tasks essential to the cultural survival of Aboriginal communities were criminalized and ceremonial objects and regalia were destroyed or sold to collectors. Native political, cultural, and spiritual leaders were jailed for facilitating traditional practices (Furness, 1995).

In a parallel administrative wave, the federal government created a reserve system in order to limit Aboriginal movement and their use of the land, despite the Royal Proclamation Act (1763) - which established British control over Aboriginal territories in the country and required that the Dominion government provide "ample” reserves and compensation in exchange for colonial land use (Harris, 2002; Tennant, 1990).

In a third, ideological wave, the government established a legally enforced Indian Residential School (IRS) system run by several Christian denominations. Initially designed to assimilate the Native population into the mainstream, it later served to separate them from it. Adhering to the Department of Indian Affairs tenet that Aboriginal children "must not be educated above the possibilities of their station," more time was spent in vocational preparation (i.e., unpaid labour) than in academic studies (Milloy, 1999). The children, starting as young as four years of age, were placed into classroom groups and segregated from their families during the school year. Conditions were generally very harsh in both physical and psychological terms. In addition to the structural violence (i.e., institutional oppression) inherent in the IRS undertaking (Sivaraksa, 1999), public humiliation and beatings were a normal response to any attempt at resistance, cultural expression, or attempts to escape (Dion Stout \& Kipling, 2003), and arbitrary emotional, cultural, spiritual, physical, and sexual violations were commonplace (e.g., Claes \& Clifton, 1998).

Finally, the fourth wave of colonization is provided by social services, a method that continues to control and exploit the Aboriginal population as effectively as the previous colonial waves (Chrisjohn, Young, \& Mauraun, 1997; Wade, 2000; Ward, 2001). "In the discourse of colonization, Aboriginal persons were violated and displaced because they were seen as deficient. In the discourse of psycholonization, Aboriginal persons [and families] are seen as deficient (damaged, disordered, dysfunctional, etc.) because they were violated and displaced" (Stephenson, 1995, p. 201).

From the post-colonial point of view, the model of individual pathology and treatment promoted in government publications regarding service provision and best practices (e.g., 
Canada, 2005) allows for the continuation of oppression through the pathologization of individuals. The result is false generosity, where the dominant power oppresses a group and then offers goods or services to "help" the oppressed group, as long as the recipients identify as weak or sick, rather than “oppressed” (e.g., Duran, 2006; Freire, 2005; Prilleltensky, 1994). As an Aboriginal colleague once asked the author: "How can you [the colonizer] offer the cure when you are the disease?” In the Aboriginal context, the individualized experience of a distressed Aboriginal person may be made sense of by means of the correlating of factors in the specific individual's life (e.g., familial mistreatment, addiction, etc.), which necessarily ignores sociocultural "wounds" of ongoing colonial oppression (Chrisjohn et al., 1997; Lykes, 1996). For example, post-colonial psychology's adherents argue that the cause of the depression among the oppressed is a normal response to the hegemonic demand that they passively accept their victimization. The "language of deficiency and dysfunction reduces to personality and syndromes behaviours that have emerged as survival or resistance to oppressive conditions" (Young \& Gerrard, 2005, p. 7) and a wide range of institutions and models have been developed to substantiate this designation (e.g., Duran, 2006; Freire, 2005; Prilleltensky, 1994; Wade, 2000). The result is a compounding of social and personal problems (Brassfield, 2001; Dion Stout \& Kipling, 2003; McCormick, 1996; Mussel, Cardiff, \& White, 2004; Royal Commission on Aboriginal Peoples [RCAP], 1995). With this in mind, any youth suicide prevention activities in Aboriginal communities must consider their possible role in further disempowering the very community it intends to serve (Samson, 2009).

\section{Discerning the Two Discourses of Suicide Prevention: An Aside}

Before exploring a post-colonial approach to suicide prevention, a confusion related to the use of the term "prevention" must be examined. When we find contradiction in a discourse, there are two points of view, two languages used to describe an issue and therefore to identify an appropriate response to that issue. Such contradictions may be accounted for by a conflation of two independent discourses that has not been discerned. In the field of suicide prevention, we are often conflating two discourses: that of safety (i.e., suicide intervention) and that of wellness (i.e., suicide prevention). This is evident in the literature's and practice's confusion regarding the term "suicide prevention". The field has created supplementary terms like primary prevention (i.e., reducing the risk of suicide in the lives of community members by education, healing, community building, social activism, etc.), secondary prevention (intervening in the event of a suicidal crisis or training community members to do so), and tertiary prevention (responding to the needs of a community after a suicide to reduce the risk of further suicides, also known as "postvention”) in an attempt to maintain two distinct conversations.

Secondary prevention is the discourse of safety, in which suicide is understood as potentially lethal and therefore a medical issue, like a heart attack. From this point of view, suicide is understood as an emergency that must be watched for (i.e., community training in the recognition and prevention of suicide) and then dealt with by "experts" (e.g., counsellors, psychologists, psychiatrists, and hospital personnel) issued with all of the surveillance and expert elements that attends a medical emergency. This is the case even though death by suicide across all populations is relatively rare, particularly when compared to the number of youth who consider suicide as a response to their distress (Bertolote et al., 2005). The primary prevention discourse is that of wellness, which understands suicide to be an indicator of personal, familial, 
and community distress (which, in the Aboriginal community, is ultimately rooted in colonial oppression). Using a critical lens, it is clear that in the face of this conflation, suicide has been medicalized, since the medical discourse is sufficiently powerful to have become the preferred (i.e., totalizing) narrative (Foucault, 1973; Gergen, 2001). However, this discernment might allow us to develop both discourses simultaneously - and may reduce the risk of one being overwhelmed by the other. The following model offers an example of this integrated approach in the Aboriginal community.

\section{A Community-based Post-colonial Approach to Youth Suicide Prevention in Aboriginal Communities}

The week-long workshop, “Through the Pain to Wellness” has offered a culturally-based post-colonial community-based youth suicide prevention program for over 15 years. Initially developed at the request of an Aboriginal program, it has changed and developed based on: the response of participants in the more than 50 communities which it has served; reviews of the literature; suicide resilience-related research with individuals and focus groups; conferences (both Aboriginally-focused and generic); and clinical work. Designed for First Nations, the primary and secondary prevention program follows a three-step model:

1. post-colonial radicalization (i.e., consciousness raising/concientization; Friere 2005) that enhances the empowerment of the participants by externalizing (e.g., White and Epston, 1990) the problem of youth suicide as a product of colonization (Kirmayer, Tate, \& Simpson, 2009); 2. youth suicide crisis intervention (a three-step model to address immediate crises); and 3. traditional cultural values-based community development model (i.e., prevention/postvention) rooted in a "bio-psycho-socio-historical-cultural-ecological-spiritual” notion of self (e.g., Duran, 2006).

This paper will continue in the same three-step format, using a less academic style that is more in keeping with (and often drawn from) the "Through the Pain to Wellness" training program participant manual.

\section{Part 1: Post-colonial Radicalization}

The first task of an Aboriginal youth suicide prevention workshop is to externalize the problem of suicide (e.g., White and Epston, 1990); that is, to identify youth suicide as a tragic, but natural, impact of colonization. The intention is to reduce the participants' sense of shame and disempowerment - the identity as "sick and dysfunctional," and therefore incapable to act independent of government sanctioned "experts" - that an oppressed community may take on in the face of crisis and suicide.

This is accomplished by the initial identification of the traditional values of wellness that have served to maintain the community for "as long as people have been here, on the land and water”. It is recognized that traditional values (e.g., respect, balance, culture, family/community role, interconnection, care, spirituality, etc.) do not naturally lead to the problem of youth suicide (or to that of addiction, violence, and other social problems in the community). A brief history of colonization follows, as described in the "Four Waves" section previously), with the participants 
International Journal of Child, Youth and Family Studies (2014) 5(1): 158-179

identifying what was stolen from the community (not "lost" as an Elder once stated, "We are not a careless people!”) by each of the insults on the community. The following list is a sample:

1. relocation/reserves (theft of territory, identity, home/belonging, economy, food sources/resources, localized spiritual places, culture, lifestyle, freedom, harmony between families, health, autonomy...);

2. theft of rights \& criminalization of culture (theft of cultural traditions/ teachings, ceremonial artifacts, history and identity, livelihood/economy, language, political autonomy/selfdetermination...);

3. residential school system (theft of family/social role, childhood, identity, culture, language, parenting skills, life skills, self-esteem, safety/trust, family harmony...);

4. social services (i.e., Aboriginal people and communities are now labelled by the government as "dysfunctional victims" who require help from the very colonizers who harmed them).

By identifying what was stolen by each wave, a locally meaningful list emerges that identifies the foundations of a healthy community (i.e., that which was stolen needs to be reclaimed for community to heal). Further, this externalization identifies the problems current in the community as a natural response to ongoing oppression, not as a weakness in the community itself. This offers a foundation for an empowered response to the problem of youth suicide (i.e., secondary prevention or suicide intervention) that draws upon the strengths in the community. Suicidal crisis is not identified as an indicator of individual mental illness, but a natural response to colonization - a problem which does not belong to the community or its members and needs to be cleansed from it. The goal is to find a better response to the pain of colonization.

\section{Part 2: Community-based Youth Suicide Intervention}

An understanding of youth suicide, including basic facts, how a person becomes suicidal, how they warn others that they are in suicidal crisis, and how to respond to a suicidal individual (i.e., suicide intervention) is offered to serve the community's immediate crisis-related needs. This two-day section of the workshop begins with an exploration of suicide facts, the most important of which is: "Suicide is about stopping the pain and hopelessness, it is not about dying. And if you can reduce a person's pain, you can reduce their suicide risk”. This is followed by an exploration of a three-step process by which a person becomes suicidal, namely, that: (a) a problem (i.e., a change or the fear of a change) that seems to be "for the worse", or the lack of a change for the better including provoking (risk) factors; can lead to (b) pain and hopelessness (which impacts the whole person - it changes how a person feels (emotion), thinks (mental), acts (physical), and visions the world (spiritual); which, after a triggering event, can result in (c) suicidal crisis.

Four signals of suicide are identified: (a) emotional alterations (i.e., either a sudden change in a person or an ongoing trend for the worse, often labelled as “depression”); (b) mental alarms (i.e., references to suicide or to being dead); (c) physical attempts or acts of self-harm (in the recent past or just disclosed); (d) spiritual arrangements (i.e., actions that you would expect anyone to make, if they believed that they were going to die very soon). 
International Journal of Child, Youth and Family Studies (2014) 5(1): 158-179 suicide:

Finally, a three-step response to suicide is offered, in terms of the three steps that lead to

1. ask the youth if they have been triggered into a suicidal crisis (the use of a direct question and risk assessment is discussed and practiced);

2. listen to their pain and helplessness (active listening is discussed and practiced); and

3. help the youth to get help, to connect to resources that will assist them to respond to their problems (a "safety and wellness plan" for all suicidal individuals, specific responses to individuals at "low”, “medium”, and "high” risk, and confidentiality/consultation are discussed and practiced).

The model is visualized as three steps down to suicidal crisis:

(1) problems $\rightarrow$ (2) pain and hopelessness $\rightarrow$ (3) suicidal crisis and, when we recognize a signal of suicide, three step back up, we: (1) ask $\rightarrow$ (2) listen (3) $\rightarrow$ help.

\section{Part 3: Culturally-rooted Model of Suicide Resilience and Prevention}

Since Aboriginal youth suicide is a result of the insult of colonization on the traditional community, it is not surprising that is it is within traditional values that Aboriginal suicide resilience can be found. Importantly, resilience can be understood as a community process, as much as an individual one (Kirmayer, Sehdev, Whitley, Dandeneau, \& Isaac, 2009). Introduced through Aboriginal suicide statistics, this third section of "Through the Pain to Wellness" provides a link between four traditional values that appear to be common to all Aboriginal communities and four resilience factors that appear to be common in suicide resilience.

As has been well documented, the traumatic impact of historical and cultural losses on Aboriginal people has led to a significantly increased suicide rate in some communities, with youth living on reserve being most at risk. However, in non-native communities, while youth suicide has also escalated, the suicide rate consistently increases in those over the age of 50, with senior citizens having a suicide risk that far exceeds that of youth (Statistics Canada, 2001). Significantly, this has not been the case with Aboriginal Elders, who have historically had a remarkably low suicide rate (RCAP, 1995).

Traditional values: The "cure" for youth suicide. The difference between Aboriginal Elders and non-native seniors appears to be cultural - based on their treatment by and engagement with their community. Specifically, unlike non-native seniors, Elders receive: (a) care for their well-being (they are not expected to look after themselves without family support as many seniors are required to do); (b) respect for their wisdom/experience (they have a meaningful voice in significant community issues, unlike seniors in the mainstream who are largely ignored); (c) a meaningful family and community role (the responsibilities of an Elder increases with age, they are not rooted in a market economic role and expectations of retirement (i.e., relative exile from community engagement) after becoming a senior); and (d) Elders are understood to hold the community's culture and spirit (unlike mainstream seniors, Elders are not considered "out of touch" due to their traditional ways; instead, they are expected to serve as guides for important decisions in the face of family or community challenges). While not all Aboriginal people "of a certain age" serve as Elders, Aboriginal Elders do not end their own lives with anywhere close to the same frequency as non-native senior citizens. 
It is within the traditional values of care, respect, a meaningful role, and culture/spirituality that the "cure" for the social and historical "disease" that is youth suicide can be found (Thira, 2009). Significantly, the experience of Elders is the opposite of that of many Aboriginal youth on reserve, who have a significantly elevated suicide rate, and who often complain that: (a) no one understands them (that the community doesn't really "care" about them); (b) they are not respected (and have no "voice" in the community); (c) they have no meaningful family or community role (except to attend school and stay out of the community's way, or to be viewed as delinquents); and (d) they are disconnected from traditional culture and spirituality.

Traditional values and youth suicide resilience. These four traditional values can be understood to contribute to psychological resilience. In this context, resilience is the ability to lead $a$ well-lived life (i.e., one that is meaningful and positive) and to value ourselves (i.e., to have self-esteem) despite difficult circumstances (e.g., Masten, 2001; Kirmayer, Sehdev, et al., 2009). For the purposes of this model, resilience in the face of youth suicide is understood to be comprised of four factors, each rooted in the four traditional values noted above: connection, rooted in care; empowerment, rooted in respect; positive identity, rooted in a meaningful role; and vision, rooted in culture and spirit (Dion Stout and Kipling, 2003; McCormick, 1996; Thira, 2009; Wade, 2000; Weaver (2002). The following subsections will explore these further:

1. Care and connection: Care is the desire to support those with whom we are connected in being happy, healthy, and safe; it is a value that motivates compassionate intervention. In psychological terms, care offers those who provide and receive it an experience of connection. Reciprocally, when we feel connected to someone or something, we care for them. Connection, sometimes called "social support", is one of the two foundations of self-esteem (discussed later; Rosenberg, 1979); however, while connection can be found with people (e.g., family, friends, etc.), it is also found with pets, places (i.e., a sense of "home" whether a house, church/ceremonial ground, or in nature), things (i.e., "transitional objects” such as photographs, jewellry, a hat, “iPod,” etc.), and spirit (however conceived).

2. Respect and empowerment. Respect is the recognition that we are capable of understanding and responding to the world in which we live. It is necessary for a person or family to be respected if their voice is to be heard by others. Respect is necessary for the recognition of self/other boundaries (both respect for others and self-respect); it suggests that even though we are connected, at some level we are separate from one another and responsible for ourselves. In terms of psychological resilience, respect offers the opportunity for empowerment. Empowerment, meaning “power with” rather than "power over” is the experience of personal or familial autonomy (i.e., the ability to make independent choices) and agency (i.e., the ability to act on those choices). When we are respected and, thus, have the opportunity to learn a new skill for ourselves, empowerment is enhanced; likewise, the provision of respect to a person (i.e., acknowledgement) offers them empowerment. The second foundation of selfesteem, empowerment is sometimes called “mastery” (Rosenberg, 1979).

3. Meaningful role and positive identity. A meaningful family and community role is the active fulfillment of our responsibility toward family and/or community (i.e., as a protector, 
provider, or teacher). Before colonization, every member of an Aboriginal community had a meaningful family and/or community role (differentiated by talent, age, gender, position, the family constellation, family membership in the community, etc.); it is a value that is essential to well-being. In psychological terms, a meaningful role offers a positive identity, a sense of our responsibility to family and community and, with it, our importance to them. When we fulfill a meaningful role, our identity becomes positive, and the more positive we feel in the face of the community, the more we will contribute.

4. Culture/spirit and vision. Culture and spirit are rich concepts that are used as a term specific to personal, family, and community experience. Culture is a foundation of our experience of being in the world, it provides the lens through which it is seen and guides our response to it (Schwartz, 1992). For many Aboriginal communities, spirituality is the basis of culture. Like culture, spirituality provides the vision of life and our role within it. It is through culture and spirit that many individuals and families find the strength and vision to live a welllived life. In psychological terms, culture and spirit yield vision - that is, our understanding of the personal, social, natural, and spiritual world and how we are meant to live within it.

The following figure offers a model that brings the traditional values and resilience factors tighter within the structure of the "medicine wheel" or "four directions" - a structure that is consistently used as requested in Aboriginal community workshops. It should be noted that the arrows indicating the relationship between the values and resilience factors are bi-directional - as noted, they enhance one another. 
International Journal of Child, Youth and Family Studies (2014) 5(1): 158-179

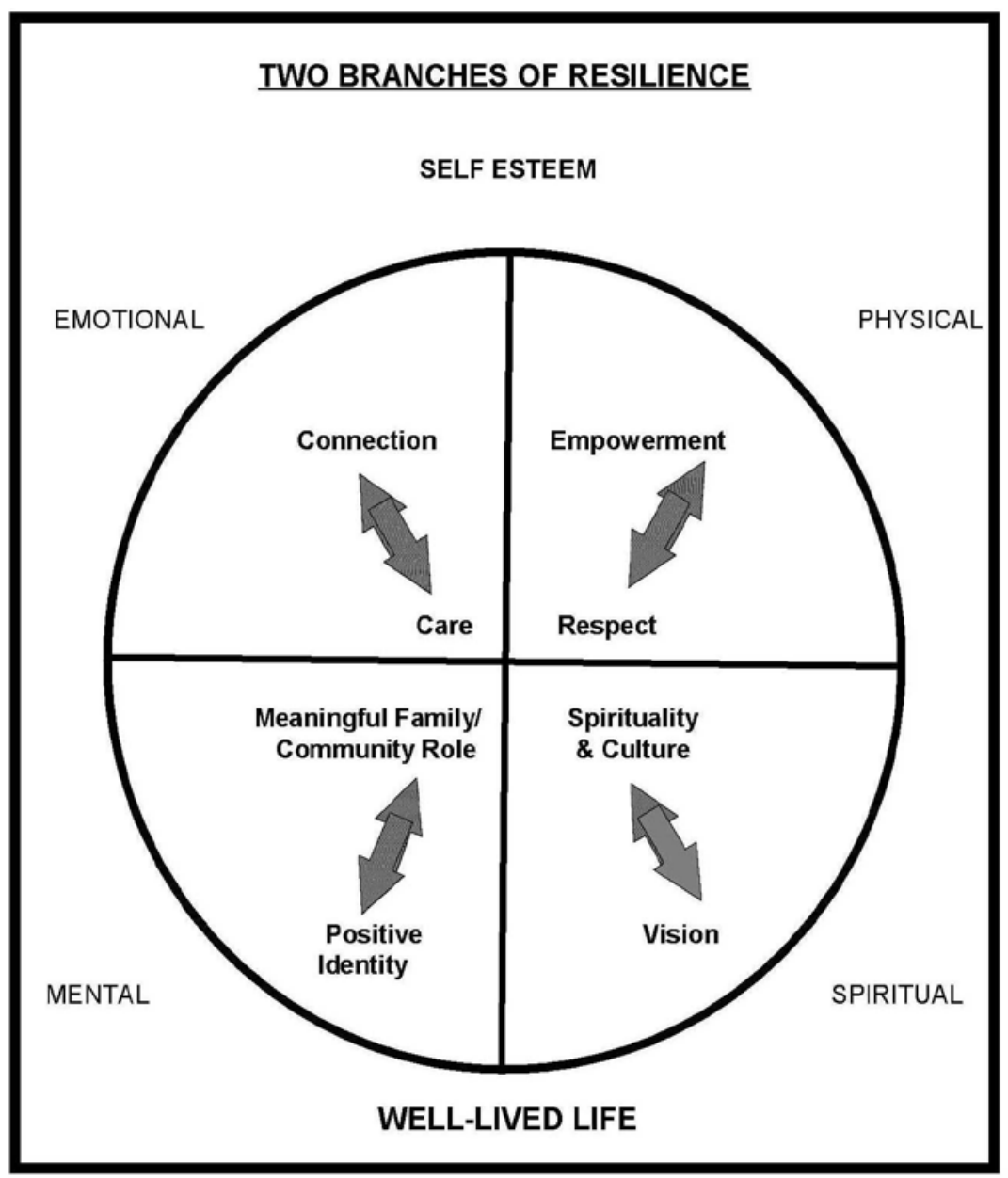

Self-esteem and the well-lived life. These four roots of resilience can be understood to grow into a tree with two branches: self-esteem and a well-lived life. Self-esteem is the valuing of ourselves. It is rooted in the sense of being connected and empowered and, therefore, comes from the experience of being cared for and respected. A well-lived life is the result of a positive identity, coming from a meaningful community/family role, and pro-social vision, rooted in a person’s culture and/or spirituality. Each “branch” will be discussed below.

Self-esteem is protection from suicide. Self-esteem is what protects us against suicide (Owens, Stryker, \& Goodman, 2001). Self-esteem is the sense of value that we have in ourselves; it is the source of our emotional strength (Rosenberg, 1979). People who have a healthy self-esteem feel that they are valuable and in control of their lives. They believe in themselves, responding with courage and creativity to face their problems from a position of strength; they seek to learn and use their skills and, finally, enlist the assistance of those around them. People who have low self-esteem feel worthless and out of control. They may "internalize" their low self-esteem and feel despair (i.e., viewing themselves as worthless and incapable of 
International Journal of Child, Youth and Family Studies (2014) 5(1): 158-179

changing their lives for the better). Experiencing themselves as victims in the face of their life, they are vulnerable to being victimized by others. Or, they may "externalize" their low selfesteem and become arrogant. Those who are arrogant compensate for their sense of being worthless by acting as if everyone else is worthless and incompetent compared to them (i.e., "I am valuable because you are not”). They often operate in the world as bullies. Their apparent self-love is false, however. Self-esteem is not built upon comparison with others, but on selfacceptance.

Self-esteem is based on two resilience foundations: connection and empowerment. However, the source of connection or empowerment must be important to the youth themselves, at the time that it is offered. For instance, youths who believe they are not accepted by their families may not have a strong sense of connection, even if they are valued by their peers. Or a youth might be an excellent artist, but if he believes that being a successful athlete is more important, he will not feel a sense of empowerment from his artwork.

Replacing rather than taking away a source of self-esteem. Some of youths' sources of connection or empowerment are not good for them or those around them. For example, if they feel a connection to their drinking and drugging buddies, or to a partner who hurts them, or if they feel empowerment when they intimidate people or steal without being caught, that is not healthy. However, when we tell a youth to stop doing something that gives them empowerment or being with someone who gives them connection, no matter how much it may hurt them or others, they will resist, because we are asking the youth to give up a source of connection or empowerment. We are asking the youth to reduce their self-esteem! And when they lose selfesteem they suffer. We should never ask a youth to give up an unhealthy source of self-esteem, but we should help them replace it with something better - better for their wellness and that of their family and community: "Never take away, always replace it with something better" is a strengths-based approach that permits youth to build on their capacity, rather than identify as "sick" or "dysfunctional".

The values of care and respect and self-esteem. Self-esteem is enhanced by the balance of the two traditional values of care and respect (which offer connection and empowerment, respectively). When the two values are not offered in balance the result is a loss of self-esteem in the youth being “helped”. If our care exceeds respect, we may attempt to take over the youth's life; to take on their life for them and to try to solve their problems, tell them what to do (i.e., give them directives in the guise of advice), or try to rescue them from the consequences of their actions (e.g., lie for them, make arrangements on their behalf that they should make for themselves, etc.). By doing so, we are telling them that we are "strong”, "know all the answers", and want to fix them. This tells them that they are "weak" and "ignorant" and "broken", that they cannot emerge from their pain without us. Alternately, respect may exceed care, particularly when we are "burning out" or after allowing the youth to cross through our personal boundaries; as a result, we may judge, criticize or punish the youth, avoid them or ignore their pain. They may feel "abandoned" or mistreated. In either case, the imbalance of these values results in the theft of self-esteem from the youth being "helped". As a consequence, they may internalize their loss (i.e., "inferiority complex"), and depend on you in their despair (i.e., become a victim), or they may externalize it (i.e., "superiority complex"), and reject you and act out with arrogance (i.e., become a bully; Adler 1956). With care and respect in balance, we never “do harm”. We 
International Journal of Child, Youth and Family Studies (2014) 5(1): 158-179

offer a suicidal youth a caring connection and the respectful opportunity to gain their own sense of empowerment in the face of their situation.

A well-lived life as the antidote to colonization. A well-lived life is made up of our identity (which emerges from a meaningful family and/or community role) and vision (which comes from culture and spirituality, however defined). A well-lived life is the ground upon which resilient individuals, families, and communities grow. It is the antidote to colonization (Kirmayer, Fletcher, \& Watt, 2009).

Many Aboriginal youth have come to view themselves according to the characteristics defined by the latest "social service" wave of colonization - as sick and dysfunctional. Thus, it is important that a youth not only try to view themselves positively (i.e., have a positive identity), but that they do this by taking on a meaningful role in their family and community, which will transform their identity from "a suicidal youth, victim, or delinquent" to that of a "volunteer for Elders" or a "caring friend or parent". This decreases youth suicide risk.

Traditionally, community members fulfilled three meaningful roles, roles necessary for the survival of the community; they were to be:

1. providers (by hunting/fishing, food gathering/preparing, house building, entertaining, facilitating ceremony, etc.);

2. protectors (as nurturers, warriors, healers, etc.); and

3. teachers (as role models, mentors, skills trainers, etc.).

These three roles continue to be essential to community survival, but Indian Residential School, which stole these roles from the students and their families, and the forces of assimilation have convinced many that only paid jobs that are part of the market economy are meaningful. This is particularly destructive today, since the economy of many reserve communities has been stolen by the colonizer as well. While being a "student" is sometimes identified as a meaningful role or "job" this is not the case: A student is travelling over a bridge to a meaningful role once they have completed study and become a plumber or counsellor, for example. Unfortunately, the mainstream elementary/secondary school curriculum does not support students in taking on meaningful roles, but emphasizes information that often has little relevance to assuming such a role in the community. Moreover, in many communities there are few jobs available that take advantage of an education; this means that a youth who pursues a career based on their education is often forced to choose exile from their family and community.

Nonetheless, in most communities, a youth's graduation from secondary school is celebrated at a community feast; but those who contribute through meaningful roles (e.g., who excel in hunting, caring for children, supporting their peers, learning to tell traditional stories, helping Elders, contributing at community events, etc.) are not equally acknowledged, even though these are the people who are living by traditional values. The result is those youth who remain in the community after leaving school often do not take on a meaningful role. They do not have an opportunity to develop a positive identity. The "Through the Pain to Wellness" program works with the participants as they identify ways that youth are contributing to the community in any of the three roles, and to identify further opportunities to make a contribution and receive recognition for their contribution. 
International Journal of Child, Youth and Family Studies (2014) 5(1): 158-179

The vision aspect of a well-lived life describes how we are meant "to live in good way". This way of living can be identified by considering the qualities of a true Elder. These qualities may include: generosity, being a teacher and healer; wisdom, patience, being cultural and spiritual; having integrity, strength, self-sufficiency and resilience; caring for others and listening from the heart; being unconditionally accepting, forgiving, non-judgmental and refusing to gossip. The program argues that, “the only 'job' of an Aboriginal youth is to become an Elder”. The goal of youth suicide prevention is not to stop suicide, but to enhance the youth's opportunity to develop their self-esteem and to live a well-lived life: to replace suicide with something better.

An example of this form of suicide intervention comes from one community in which a small group of youth in their late teens were identified to be "at risk". They were asked to go to an Elder and learn a "traditional" story to teach to children in the community daycare. (Learning the story was not the intervention, since being a student is not a meaningful role). The youth were recognized as teachers at the next community feast. In this example, the opportunity to contribute offered the youth connection with both the Elders and the children, empowerment because they learned how to tell an important story and they were acknowledged at the feast, an identity as "teacher”, and enhancement of their vision by playing a part in the community's cultural heritage and development.

\section{The Community is the Medicine}

Since youth suicide impacts the whole community, the whole community can respond to a crisis in one of its individuals, its families, or the community at large. The capacity was there before contact and it's there now, because it is rooted in the traditional values of care, respect, a meaningful family/community role, and culture/spirituality. However, to recognize and benefit from the wisdom and strength of the community, it is necessary to step outside the limited view of the community and its resources and escape dependency on government-sanctioned "false generosity” that has been the key to the fourth wave of colonization.

The identification of a rich collection of underutilized resources, beyond those offered by the mainstream "mental health" model, resources available to youth within even the most remote communities, is undertaken in the "Through the Pain to Wellness" program. This requires two steps: first, the redefinition of self from an individualistic view (i.e., in which a person "ends" at the outside of their skin) to a collectivist view (i.e., the self as a "self/community life-world"); and second, re-visioning the community as a resilience resource network (i.e., a site for the enhancement of connection, empowerment, positive identity, and vision), rather than the site of the problem.

\section{Self / Community Life-World}

A self/community life-world is a conceptual integration of our biological, psychological, social, cultural, historical, ecological, and spiritual experience of ourselves and our context. It simultaneously defines identity (i.e., it is existential) and describes the context in which we live our life (i.e., it is experiential). Surrounding (and within) a youth, a self-community can be considered to be made up of six interdependent parts: 
International Journal of Child, Youth and Family Studies (2014) 5(1): 158-179

1. Self: resources to be found within oneself;

2. Family: (or Clan) as identified by oneself;

3. Individuals: specific people, generally known by name (e.g., friends, professional and non-professional caregivers, etc.);

4. The Community: taken at large (i.e., whose membership may change, but the identity of the collective or role remains, such as agencies, services, community centres and schools, support groups, sports teams, etc.;

5. Outside Community: forces or individuals outside the community which can have an impact (e.g., neighbouring communities, the Internet, regional services, books, political leaders, heroes or youth idols, the media, etc.); and

6. Nature and Spirit: the non-manmade environment in which a person lives and the nonmaterial forces that people experience.

\section{Community Resource Map}

When combined with the four factors of resilience, the community (as divided into six parts) creates a community resource map that is able to offer individuals, families, and the community as a whole, opportunities for: (a) connection; (b) empowerment; (c) a positive identity; and (d) vision. A Community Resource Map provides a basis for community-engaged crisis intervention, effective postvention, and community-based primary prevention. This can be depicted in the graphic that follows.

Community resource map and youth suicide intervention. After a youth is safe from immediate risk of suicide, the crisis (and therefore, the opportunity) has not passed. The problem(s) that led to the pain of crisis must be dealt with so that the crisis can ultimately become an opportunity to enhance resilience. While it is ultimately the person in crisis who will identify resilience resources suitable for them, it is important to work with them to identify at least one community resource for every government-sanctioned funded resource. For example, a response to low suicide risk may include counselling. However, healing may also be facilitated by time with an Elder who may teach the youth what it is to be a man, or may recommend time spent fishing with an older family member thus affording an opportunity to contribute fish to other Elders. In this case, the Elder's wellness is also enhanced by being called upon as an Elder, and the family member driving the boat will feel engaged in the youth's healing and learning. Interestingly, the more "traditional" the activity, the richer its impact in terms of resilience enhancement. More examples from community resource-mapping for a youth in suicidal crisis are noted below. 
International Journal of Child, Youth and Family Studies (2014) 5(1): 158-179

\section{COMMUNITY RESOURCE MAP}

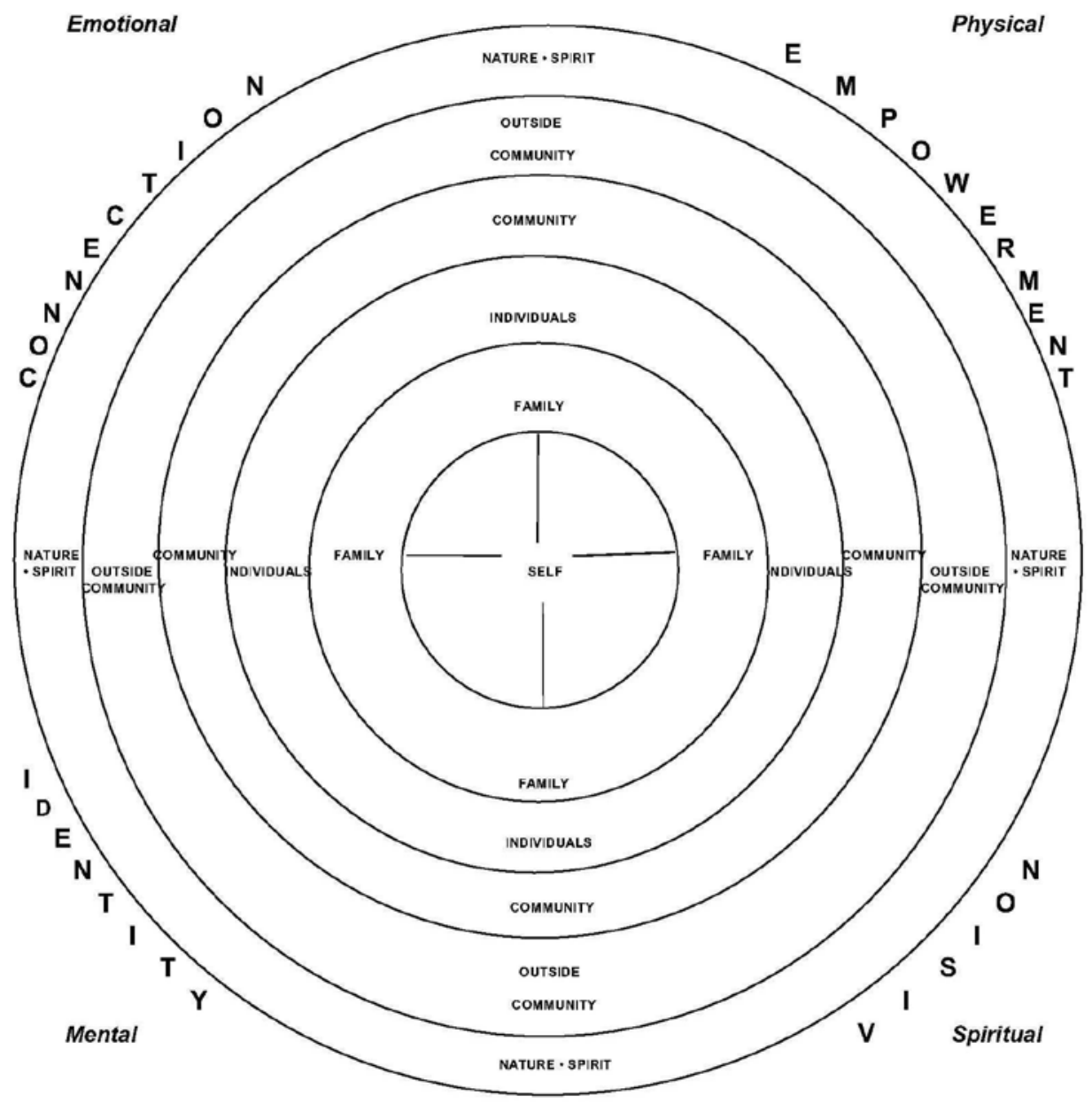




\begin{tabular}{|c|c|c|c|c|}
\hline & CONNECTION & $\begin{array}{l}\text { EMPOWER- } \\
\text { MENT }\end{array}$ & $\begin{array}{c}\text { IDENTITY } \\
\text { (Meaningful Role) }\end{array}$ & VISION \\
\hline SELF & $\begin{array}{l}\text { belief in oneself, hope, } \\
\text { creativity, self-care, } \\
\text { empathy, etc. }\end{array}$ & $\begin{array}{l}\text { self-discipline, previous } \\
\text { resilience, courage, } \\
\text { responsibility, strength, } \\
\text { etc. }\end{array}$ & $\begin{array}{l}\text { sense of self as a } \\
\text { provider, protector, } \\
\text { and teacher }\end{array}$ & $\begin{array}{l}\text { ceremony, prayer, faith, } \\
\text { meditation, etc. }\end{array}$ \\
\hline $\begin{array}{l}\text { FAMILY } \\
\text { and/or } \\
\text { CLAN }\end{array}$ & $\begin{array}{l}\text { participate in activities } \\
\text { that enhance the } \\
\text { experience of love and } \\
\text { support for and from } \\
\text { family members of all } \\
\text { generations, get to } \\
\text { know extended family } \\
\text { members }\end{array}$ & $\begin{array}{l}\text { participate in family } \\
\text { events/ activities, time } \\
\text { with children, making } \\
\text { amends, family-related } \\
\text { chores and support, } \\
\text { etc. }\end{array}$ & $\begin{array}{l}\text { learn family history, } \\
\text { take on meaningful } \\
\text { family role (protect } \\
\text { children, provide } \\
\text { firewood, teach a skill), } \\
\text { enhance view of family } \\
\text { and its role by the rest } \\
\text { of community, contact } \\
\text { estranged family, etc. }\end{array}$ & $\begin{array}{l}\text { learn traditional } \\
\text { family/clan stories, take } \\
\text { on Traditional role in } \\
\text { the family, learn and } \\
\text { perform family-owned } \\
\text { songs/ dances/ } \\
\text { ceremonies, etc. }\end{array}$ \\
\hline $\begin{array}{l}\text { INDIVIDUALS } \\
\text { Youth }\end{array}$ & $\begin{array}{l}\text { spend positive time } \\
\text { with friends, peer- } \\
\text { helpers, friend's } \\
\text { children, etc. }\end{array}$ & $\begin{array}{l}\text { volunteer time with } \\
\text { younger children; } \\
\text { participation in team } \\
\text { sports/ activities/clubs }\end{array}$ & $\begin{array}{l}\text { role model, sober } \\
\text { friend, protect, } \\
\text { mentor, teacher, etc. }\end{array}$ & $\begin{array}{l}\text { learn/perform traditional } \\
\text { songs/dances/ } \\
\text { ceremonies, etc. }\end{array}$ \\
\hline Adults & $\begin{array}{l}\text { seek support from } \\
\text { adult friend, Elder, } \\
\text { professional } \\
\text { (counsellor, teacher, } \\
\text { doctor...), sponsor, } \\
\text { coach, mentor, etc. }\end{array}$ & $\begin{array}{l}\text { volunteer help for } \\
\text { elders (chop wood, } \\
\text { clear yard, drive to } \\
\text { events...), learn a skill } \\
\text { from someone, etc. }\end{array}$ & $\begin{array}{l}\text { provide for a friend by } \\
\text { babysitting or fishing, } \\
\text { protect a child or client, } \\
\text { teach a skill, etc. }\end{array}$ & $\begin{array}{l}\text { seek assistance from a } \\
\text { spiritual guide/Elder, } \\
\text { etc. }\end{array}$ \\
\hline COMMUNITY & $\begin{array}{l}\text { social/human services, } \\
\text { support/self-help } \\
\text { groups, community } \\
\text { programs, school- } \\
\text { based support, } \\
\text { community centre } \\
\text { programs, healing } \\
\text { workshops, youth } \\
\text { centres, etc. }\end{array}$ & $\begin{array}{l}\text { get a haircut, seek } \\
\text { return to schooling, } \\
\text { volunteer, attend } \\
\text { training workshops, } \\
\text { develop a resume, } \\
\text { apply for work, etc. }\end{array}$ & $\begin{array}{l}\text { connect to cultural and } \\
\text { spiritual identity; } \\
\text { volunteer (e.g., clean } \\
\text { corner store, help } \\
\text { arrange community } \\
\text { event), invite "house } \\
\text { family" involvement, } \\
\text { start a support group, } \\
\text { etc. }\end{array}$ & $\begin{array}{l}\text { engage with } \\
\text { congregation, spiritually } \\
\text { designated buildings, } \\
\text { community ceremonies, } \\
\text { spiritual role in the } \\
\text { community, etc. }\end{array}$ \\
\hline $\begin{array}{l}\text { OUTSIDE } \\
\text { COMMUNITY }\end{array}$ & $\begin{array}{l}\text { "long-distance" } \\
\text { friends/family, } \\
\text { treatment/healing } \\
\text { centre, outpatient } \\
\text { programs, crisis line, } \\
\text { Internet chat rooms, } \\
\text { national organizations, } \\
\text { music, etc. }\end{array}$ & $\begin{array}{l}\text { attend treatment } \\
\text { program, write to } \\
\text { media/social activism, } \\
\text { complete detox } \\
\text { program, inter- } \\
\text { community activity } \\
\text { (e.g., sports/cultural } \\
\text { exchanges), etc. }\end{array}$ & $\begin{array}{l}\text { Aboriginal/ National } \\
\text { identity, teach others } \\
\text { about culture or social } \\
\text { history, develop world- } \\
\text { wide Indigenous } \\
\text { relationships, etc. }\end{array}$ & $\begin{array}{l}\text { participate in inter-tribal } \\
\text { ceremonies ("pow } \\
\text { wows") and/or } \\
\text { social/cultural } \\
\text { development initiatives, } \\
\text { etc. }\end{array}$ \\
\hline NATUREISPIRIT & $\begin{array}{l}\text { time on the Land or } \\
\text { water (camping or } \\
\text { sitting), prayer/ } \\
\text { ceremony, etc. }\end{array}$ & $\begin{array}{l}\text { fishing, hiking, hunting, } \\
\text { gathering, food } \\
\text { preparing, etc. }\end{array}$ & $\begin{array}{l}\text { sharing one's catch, } \\
\text { conservation, actively } \\
\text { contributing to spiritual } \\
\text { community, etc. }\end{array}$ & $\begin{array}{l}\text { cleansing ceremonies, } \\
\text { Spirit quest, sacred } \\
\text { places, sweat lodges, } \\
\text { walking around home } \\
\text { territory, etc. }\end{array}$ \\
\hline
\end{tabular}

As the community helps the person in crisis, it reduces its dependency on governmentsanctioned programs that identify the community and its members as sick or dysfunctional. Specifically: (a) its connection is enhanced (as people and programs work together and the conflicts that surround a person in crisis are resolved); (b) its empowerment is enhanced (as the community resolves its own issues); (c) it provides meaningful roles (as members of the community are called upon to contribute and collective service of the youth in distress helps to dispel the community's colonial identity as a dysfunctional victim); and (d) this community mobilization is cultural because traditionally the community took care of its own. The 
International Journal of Child, Youth and Family Studies (2014) 5(1): 158-179

community-based response to an individual's distress - distress which can itself be understood as an expression of the community's distress rooted in the wounds of colonization - heals the community and the individual simultaneously. In other words, the community transforms itself one crisis at a time!

Community resource map and youth suicide postvention. Not every suicide can be prevented and the impact of a suicidal death on the "survivors" can be significant. To support the community and reduce the risk of further suicides, a postvention (i.e., tertiary prevention) protocol provides initial coordinated steps to long-term recovery for a community and its members. The community resource map can guide the development of protocol, which can act to build the self-esteem of the community as a whole in the face of the tragedy, ensure that those who need support get it, and provide necessary information and education. It is important that each community have, first, a Community Response Team (i.e., a team made up of human service workers, first responders, community leaders, and natural caregivers that can respond to individuals in crisis and critical community incidents), and second, Postvention Protocol (i.e., the tasks that a community can undertake to support community members and reduce the risk of contagion. A discussion of Team development and the identification of the Protocol tasks are included the "Through the Pain to Wellness" program. Led by a Community Response Team, the Protocol allows for the enhancement of the community's self-esteem (supportive connection and a sense of collective empowerment) across and within the community in the face of the tragedy.

Community resource map and primary prevention: Visioning the future. It can be valuable for community members committed to wellness and social development to use the Community Resource Map to envision a suicide-free community. In other words, to imagine, in specific and practical terms, the individual, family, and community's activities/roles, social networks, services, and programs responsible for greater connection, empowerment, and engagement in roles that create a positive social identity, and activities that promote a culturally rooted vision. To this end, a visualization of a suicide-free community, five years in the future, is facilitated, using the Community Resource Map as a template. An example of primary prevention that a community discussed in the "Through the Pain to Wellness" program is described below. This is an example of community-based primary suicide prevention:

The “Three Generations of Youth: Youth Leadership-Mentor Program” co-created with an Aboriginal Community Wellness Team, is based on the following premise: Before colonization, youth played essential roles in the community and while recently youth have been told "you are the future", they have not been given a role in making the future a reality; they have been told that the traditions will guide them, but they have not been given the opportunity to play traditional (i.e., meaningful) roles in the community. This program assists Aboriginal youth in taking on their traditional leadership and mentorship roles. The program development and implementation follows four steps. First, its development begins with three days of consultation, during which participants were asked to answer 3 questions: What was it like to be a youth? What do youth need? What would you recommend be included in a mentorship training program? 
On the first day, Elders were asked these questions while youth watched and listened and then responded to what they heard in the last part of the day. On the second day, youth were asked the questions, while Elders listened and then commented in the last part of the day. Finally, on the third day, the questions were put to front-line professionals and community health directors. In this way the program design is rooted in the community's unique culture and perceived prevention needs. In the second "training for trainers" step, “older youth" (19 to 24 years old) received a five-day "Leadership Training Program" that offered an opportunity for them to become facilitators of a two-day workshop designed to train peer-mentors. In the third stage, “younger youth” (13 to 18 years old) received the two-day "Mentorship Training Program”. In the fourth step, the children received caring connection and respectful empowerment opportunities from the youth mentors in their community and learned that they have an opportunity to become mentors in their turn.

\section{Conclusion}

From a post-colonial standpoint, youth suicide is the product of oppression. It is a natural, although tragic, reaction to the ongoing impacts of the colonial enterprise on communities, families, and individuals. Rather than encouraging dependency on "expert” outsiders or attempting to "fix" the community and its members, post-colonial Aboriginal youth suicide prevention requires the engagement of the community's capacity to enhance family and individual wellness in the face of the oppression. This approach is true community-based prevention: assisting the community to build stronger connections, empowering the community to respond to its own issues, offering a shift in community identity (from dysfunctional victim to resilient healer), and transforming the community's vision (from colonized "Indian" to a culturally strong Aboriginal Nation). Rooted in traditional cultural values, a community-based response to suicidal crisis becomes an opportunity for the enhancement of individual resilience, family healing, and community transformation. 
International Journal of Child, Youth and Family Studies (2014) 5(1): 158-179

\section{References}

Adler, A. (1956). The individual psychology of Alfred Adler (H. L. Ansbacher \& R. R. Ansbacher, Eds.). New York: Basic Books.

Atleo, M. (1997). First Nations healing: Dominance or health. The Canadian Journal for the Study of Adult Education, 11(2): 63-67.

Bertolote, J. M., Fleischmann, A., De Leo, D., Bolhar, J., Botega, N., De Silva, D., et al. (2005). Suicide attempts, plans, and ideation in culturally diverse sites: The WHO SUPRE-MISS community survey. Psychological Medicine, 2005, 35, 1457-1465. Cambridge, UK: Cambridge University Press. http//dox. Doi.org: 10.101 7/S0033291 705005404.

Bhargava, R. (1992). Individualism in social science: Forms and limits of a methodology. New York: Oxford University Press. http://dx.doi.org/10.2307/2076119

Billington, T. (1996). Pathologizing children: Psychology in education. In E. Burman (Ed.), Psychology discourse practice: From regulation to discourse (pp. 37-54). Bristol, PA: Taylor and Francis.

Brassfield, C. (2001). Residential school syndrome. British Columbia Medical Journal, 43(2), 78-81.

Burman, E. (1996). Psychology discourse practice: From regulation to discourse. In E. Burman (Ed.), Psychology discourse practice: From regulation to discourse (pp. 1-14). Bristol, PA: Taylor and Francis.

Canada. (2005). Indian residential schools mental health support program: Program framework. Ottawa: Indian Residential Schools Resolution Canada.

Chrisjohn, R., Young, S., \& Mauraun, M. (1997). The circle game: Shadows and substance in the Indian residential school experience in Canada. Penticton, BC: Theytus Books.

Claes, R., \& Clifton, D. (1998). Needs and expectations for redress of victims of abuse at residential schools. Ottawa: Law Commission of Canada.

Dana, R. (1996). Culturally competent assessment practice in the United States. Journal of Personality Assessment, 66(3), 472-487. http://dx.doi.org/10.1207/s15327752jpa6603_2

Dion Stout, M., \& Kipling, G. (2003). Aboriginal people, resilience, and the residential school legacy. Ottawa: Aboriginal Healing Foundation.

Duran, E. (2006). Healing the soul wound: Counseling with American Indians and other native peoples. New York: Teachers College Press.

Foucault, M. (1973). The birth of the clinic: Archaeology of medical perception (A. M. Sheridan, Trans.). London: Routledge. 
International Journal of Child, Youth and Family Studies (2014) 5(1): 158-179

Freire, P. (2005). Pedagogy of the oppressed. New York: Continuum Press. (Original work published 1970)

Furness, E. (1995). Victims of benevolence: The dark legacy of the William's Lake residential school. Vancouver, BC: Arsenal Pulp Press.http://dx.doi.org/10.2307/25605824

Gergen, K. (2001). Social construction in context. Thousand Oaks, CA: Sage.

Gutierrez, L., \& Lewis, E. (1999). Empowering women of colour. New York: Columbia University Press.

Harris, C. (2002). Making Native space: Colonialism, resistance and reserves in British Columbia. Vancouver: UBC Press.

Heenan, C. (1996). Feminist theory and its discontents. In E. Burman (Ed.), Psychology discourse practice: From regulation to discourse (pp. 55-72). Bristol, PA: Taylor and Francis.

Ingleby, D. (Ed.). (1980). Critical psychiatry: The politics of mental health. New York: Pantheon Books.

Kirmayer, L. J., Fletcher, C., \& Watt, R. (2009). Locating the ecocentric self: Inuit concepts of mental health and wellness. In L. J. Kirmayer \& G. G. Valaskakis (Eds.), Healing traditions: The mental health of Aboriginal peoples in Canada (pp. 3-35). Vancouver: UBC Press.

Kirmayer, L. J., Sehdev, M., Whitley, R., Dandeneau, S. F., \& Isaac, C. (2009). Community resilience: Models, metaphors and measures. Journal of Aboriginal Health, 7(1), 62-117.

Kirmayer, L. J.,Tate, C., \& Simpson, C. (2009). The mental health of aboriginal peoples in Canada: Transformations of identity. In L. J. Kirmayer \& G. G. Valaskakis (Eds.), Healing traditions: The mental health of Aboriginal peoples in Canada (pp. 3-35). Vancouver: UBC Press.

Kleinman, A. (1988). Rethinking psychiatry: From cultural category to personal experience. Toronto: Collier Macmillan Canada.

Lykes, M. B. (1996). Meaning making in a context of genocide and silencing. In M. B. Lykes, A. Banuazizi, L. Ramsay, \& M. Morris (Eds.), Myths about the powerless: Contesting social inequities (pp. 159-178). Philadelphia: Temple University Press.

Masten, A. (2001). Ordinary magic: Resilience processes in development. American Psychologist, 56(3), 227-238. http://dx.doi.org/10.1037//0003-066x.56.3.227

McCormick, R. (1996). The facilitation of healing for the First Nations people of British Columbia. Canadian Journal of Native Education, 21(2), 249-322. 
International Journal of Child, Youth and Family Studies (2014) 5(1): 158-179

Milloy, J. (1999). A national crime: The Canadian government and the residential school system: 1879-1986. Winnipeg, MN: University of Winnipeg Press.

Mussel, B., Cardiff, K., \& White, J. (2004). The mental health and well-being of Aboriginal children and youth: Guidance for new approaches and services. Chilliwack, BC: British Columbia Ministry for Children and Family Development.

Owens, T., Stryker, S., \& Goodman, N. (Eds.). (2001). Extending self-esteem theory and research: Sociological and psychological currents. Cambridge, UK: Cambridge University Press. http://dx.doi.org/10.1017/cbo9780511527739

Prilleltensky, I. (1994). The morals and politics of psychology: Psychological discourse and the status quo. New York: State University of New York.

Rosenberg, M. (1979). Conceiving the self. New York: Basic Books.

Royal Commission on Aboriginal Peoples (RCAP). (1995). Choosing life: Suicide among Aboriginal people. Ottawa: Author.

Samson, C. (2009). A colonial double-bind: Social and historical contexts of Innu mental health. In L. J. Kirmayer \& G. G. Valaskakis (Eds.), Healing traditions: The mental health of Aboriginal peoples in Canada (pp. 109-139). Vancouver: UBC Press.

Satzewich, V. (1998). Race, racism and radicalization: Contested concepts. In V. Satzewich (Ed.), Racism and social inequality in Canada: Concepts, controversies and strategies of resistance (pp. 25-45). Toronto: Thompson Education Publishing, Inc.

Schwartz, T. (1992). Anthropology and psychology: An unrequited relationship. In T. Schwartz, G. White, \& C. Lutz (Eds.), New directions in psychological anthropology (pp. 324349). Cambridge, UK: Cambridge University Press. http://dx.doi.org/10.1017/cbo9780511621857.017

Sivaraksa, S. (1999). Global healing: Essays and interviews on structural violence social development and spiritual transformation. Bangkok: Thai Inter-Religious Commission for Development.

Smith, L. T. (1998). Decolonizing methodologies: Research and indigenous peoples. New York: Zed Books.

Statistics Canada. (2001). Aboriginal Peoples in Canada. Ottawa: Canadian Centre for Justice Statistics (Ministry of Industry).

Stephenson, P. (1995). A persistent spirit: Toward understanding Aboriginal health in British Columbia. Victoria, BC: Western Geographical Press.

Tennant, P. (1990). Aboriginal people and politics: The Indian land question in British Columbia, 1849-1989. Vancouver: University of British Columbia Press. 
International Journal of Child, Youth and Family Studies (2014) 5(1): 158-179

Thira, D. (2009). And I live it. (Doctoral dissertation). Retrieved from by Proquest, Umi Dissertation Publishing. (SPM6164190403).

Wade, A. (2000). Resistance knowledges: Therapy with aboriginal persons who have experienced violence. In P. Stephenson, S. Elliot, L. Foster, \& J. Harris (Eds.), A persistent spirit: Towards understanding aboriginal health in British Columbia (pp. 167206). Victoria BC: University of Victoria.

Ward, K. (2001). Residential Schools in British Columbia. The Journey.[NOTE: Incomplete reference; Is this from a journal? Or is it a book with location/publisher?]

Weaver, H. N. (2002). Perspectives on wellness: Journeys on the red road. Journal of Sociology and Social Welfare, 24(1), 5-15.

White, M., \& Epston, D. (1990). Narrative means to therapeutic ends. New York: Norton.

Young, A. (1996). Bodily memory and traumatic memory. In P. Antze \& M. Lambek (Eds.), Tense past: Cultural essays in trauma and memory (pp. 89-102). New York: Routledge.

Young, A., \& Gerrard, M. (2005). Educating bodies for self-determination: A decolonizing strategy. Unpublished manuscript, Vancouver, BC.

Youngblood Henderson, J. (2000). Postcolonial ghost dancing: Diagnosing European colonialism. In M. Battiste (Ed.), Reclaiming Indigenous voice and vision (pp. 161-171). Vancouver: University of British Columbia Press. 